\title{
Myeloperoxidase Activity in Peripheral Blood, Neutrophil Crevicular Fluid and Whole Saliva of Patients with Periodontal Disease
}

\author{
Cem ÖVER ${ }^{1}$, Nermin YAMALIK ${ }^{1}$, Ezel YAVUZYILMAZ ${ }^{1}$, Fügen ERSOY ${ }^{2}$ \\ and Kenan ERATALAY ${ }^{1}$
}

(Received 28 December 1992 and accepted 22 July 1993)

Key words: GCF, periodontal disease, myeloperoxidase

\begin{abstract}
Mean levels of myeloperoxidase (MPO) activity were determined in samples of gingival crevicular fluid (GCF), whole saliva and peripheral blood neutrophils from patients with rapidly progressive periodontitis (RPP) and adult periodontitis (AP) using a spectrophotometric method. The mean neutrophil MPO activity in the RPP group was $563.1 \pm 137.05 \mathrm{U} / 1 \times 10^{6} /$ $\mathrm{ml}$, that in the AP group was $483.3 \pm 88.81 \mathrm{U} / 1 \times 10^{6} / \mathrm{ml}$, and that in the control group was $220.6 \pm 26.7 \mathrm{U} / 1 \times 10^{6} / \mathrm{ml}$. The mean GCF MPO activity in the RPP group was $15.13 \pm 2.34$ $\mathrm{U} / \mathrm{mg}$, which was significantly higher than in the other two groups. The mean whole saliva MPO activity in the RPP group was $0.14 \pm 0.04 \mathrm{U} / \mathrm{ml}$, that in the AP group was $0.11 \pm 0.02 \mathrm{U} / \mathrm{ml}$, and that in the control group was $0.05 \pm 0.06 \mathrm{U} / \mathrm{ml}$. MPO activity detected in the samples was significantly increased in the patient groups when compared to the healthy subjects. The highest MPO activity was found in the RPP group. The present findings suggest a relationship between MPO activity and the pattern and severity of periodontal breakdown. Also the increased MPO activity in periodontally diseased patients can be attributed to the increased number of neutrophils, the degranulation of these cells and also their hyperactive state in the presence of chronic antigenic stimulation.
\end{abstract}

\section{Introduction}

The importance of host defence mechanisms in the pathogenesis of periodontal disease has been well demonstrated in recent years ${ }^{[1-4]}$. The accumulation of neutrophils, macrophages and lymphocytes in the injured or infected area is one of the most important steps in host defence ${ }^{[5,6]}$. Among these cells, neutrophils have the most significant role, since they establish the first defence barrier against the microbial challenge ${ }^{[2,5-8]}$. A decreased number of neutrophils and/or impairment of their function is detrimental to the maintenance of periodontal health ${ }^{[2,7-10]}$.

Neutrophils contain the necessary material for the phagocytosis and killing of pathogenic microorganisms, including lysozyme, lactoferrin, alkaline phosphatase, acid hydrolases, cationic proteins and also myeloperoxidase $(\mathrm{MPO})^{[11-13]}$. MPO, which is present in the azurophilic granules of neutrophils, is one of the enzymes considered to play a role in the host response, especially in oxygen-mediated defence mechanisms ${ }^{[14,15]}$. The MPO $-\mathrm{H}_{2} \mathrm{O}_{2}$ halide system has been shown to have an antimicrobial function ${ }^{[14,16-18]}$, and it is suggested to be effective for killing of Escherichia coli, Lactobacillus acidophilus, Staphylococcus aureus and also a periodontopathic microorganism, Actinobacillus actinomycetemcomitans ${ }^{[14,17,19]}$.

Studies on the relationship between MPO activity and periodontal disease have revealed

1 Department of Periodontology, Faculty of Dentistry, University of Hacettepe, Ankara, Turkey

2 Children's Hospital, Immunology Unit, University of Hacettepe, Ankara, Turkey

To whom all correspondence should be addressed: Dr. Nermin YAMALIK, Department of Periodontology, Faculty of Dentistry, University of Hacettepe, Ankara, TURKEY 06100 
increased MPO activity in gingival crevicular fluid (GCF) and crevicular neutrophils from periodontally diseased sites ${ }^{[13,20-22]}$. It has also been demonstrated that GCF MPO activity is significantly decreased following periodontal therapy ${ }^{[13,21]}$. Evaluation of MPO activity is therefore suggested to be beneficial in the assessment of inflammatory periodontal disease $\mathrm{e}^{[21]}$.

However, the previous studies have ignored specific periodontal diseases with different patterns and severities of periodontal breakdown. Therefore, determination of MPO activity in patients showing rapid and severe periodontal breakdown and also in those with relatively less periodontal destruction, may help us to better understand the role of this enzyme in the pathogenesis of periodontal disease.

The aim of the present study was to determine the MPO activity in peripheral blood neutrophils, whole saliva and GCF samples from patients with rapidly progressive periodontitis (RPP) and adult periodontitis (AP).

\section{Materials and Methods}

Patient selection: Ten systemically healthy (4 female and 6 male) patients who were diagnosed clinically and radiographically as having AP according to their age, the pattern of periodontal breakdown, and the correlation of periodontal destruction with existing local factors, were chosen from among patients who were in need of periodontal therapy. Ten patients ( 5 female and 5 male) who were diagnosed as having RPP, were chosen according to their age, the pattern and severity of periodontal destruction, the onset of the disease and the negative correlation between periodontal breakdown and local factors present. Patients with missing maxillary incisors canines and with a recent history of antibiotic and/or antiinflammatory drug medication were excluded. Ten systemically and periodontally healthy subjects chosen from among dental students and staff, constituted the control group. The age range was 17-33 yr for the RPP group, 37-65 yr for the AP group and 19-33 yr for the control group. All of the subjects were informed about the experimental design and their written consent was obtained. Care was taken to ensure that none of the subjects had received any periodontal treatment in the previous 6 months.

Clinical studies: Clinical data concerning pocket depth, bleeding on probing, gingival index and the plaque index of LöE AND SILLNESS ${ }^{[23]}$ were recorded for every subject before the collection of GCF, whole saliva and blood samples.

Collection of GCF, whole saliva and blood samples: GCF samples were obtained using paper strips according to the method described by RUDIN et al. ${ }^{[24]}$ before recording of any clinical parameter. In order to eliminate the risk of contamination with saliva, GCF was collected only from the vestibular aspects of maxillary incisor canine teeth. The area was isolated with cotton rolls and gently air-dried. The paper strips, with standard dimensions $(2 \times 10 \mathrm{~mm})$, with a standard 1-mm notch at the entrance end, were inserted into the sulcus (the 1-mm notch serving as a safeguard against deeper penetration). The strips were left in the sulcus for 3 min, then weighed in plastic tubes after absorption of GCF. The amount of collected GCF was determined by subtracting the combined weight of the paper and tube before GCF collection from that after GCF cllection. The strips containing the sampled GCF were then transferred immediately to a tube containing $0.1 \mathrm{ml} \mathrm{NaPO}$ buffer ( $\mathrm{pH} 7.4$ ) and stored at $-70^{\circ} \mathrm{C}$ until the day of analysis.

Five milliliters of unstimulated whole saliva was collected into a sterile glass tube by expectoration. Whole saliva samples were stored at $-70^{\circ} \mathrm{C}$.

Ten milliliters of venous blood was drawn from each of the subjects into a sterile syringe containing heparin $(20$ units $/ \mathrm{ml})$, in order to determine the peripheral neutrophil MPO activity, and neutrophils were separated from the blood samples.

\section{Laboratory Studies}

Isolation of neutrophils: Heparinized peripheral blood samples were obtained from a 
peripheral vein. Polymorphonuclear-rich cells were obtained by the two-step technique described by Boyum ${ }^{[25]}$. After 3 washings in medium 199 (Wellcome, U. K. ), polymorphonuclear leukocytes were suspended in the same medium at a final concentration of $1 \times 10^{6} / \mathrm{ml}$. The neutrophils were then stored at $-70^{\circ} \mathrm{C}$.

On the day of assay, whole saliva, GCF and neutrophil suspension samples were placed in an ultrasonic bath and homogenized for $30 \mathrm{~min}$. Using diaminobenzidine (Sigma, U. S. A. ) as a substrate, enzyme activity in the samples was determined by a modification of the method of HANKER et al. ${ }^{[26]}$ Upon addition of $\mathrm{H}_{2} \mathrm{O}_{2}$ and its reaction with MPO in the samples, the diaminobenzidine became oxidized and changed to a light brown color. The amount of MPO was then quantified using an LKB spectrophotometer at $22^{\circ} \mathrm{C}$. The reaction was followed for 10 min at $460 \mathrm{~nm}$.

Statistical studies: Differences among the groups with regard to clinical parameters and MPO activity in the tested samples were evaluated by Kruskall-Wallis one-way analysis of variance by rank $^{[27]}$.

\section{Results}

Clinical findings: Data on clinical parameters are given in Table 1. All of the clinical parameters, except the number of sites negative for bleeding, were found to be significantly increased in both of the patient groups, when compared with the control group $(p<0.05)$. The highest values of the clinical parameters, except the number of sites negative for bleeding, were detected in the RPP group, and the increases were statistically significant $(\mathrm{p}<0.05)$.

Laboratory findings: Data on MPO activity in the samples are given in Table 2. The levels of MPO activity in the neutrophils and whole saliva samples from the two patient groups were significantly higher than in the control group $(\mathrm{p}<0.05)$. The highest GCF, whole saliva and neutrophil MPO activity was noted in patients with RPP $(\mathrm{p}<0.05)$. The difference in GCF MPO activity between the AP and the control group was not significant $(\mathrm{p}>0.05)$. Among the samples studied, neutrophil samples had the highest MPO activity

Table 1 Data related to clinical findings (mean \pm S. D.)

\begin{tabular}{lcccccc}
\hline & $\begin{array}{c}\text { Pocket Depth } \\
(\mathrm{mm})\end{array}$ & $\begin{array}{c}\text { Gingival } \\
\text { Index }\end{array}$ & $\begin{array}{c}\text { Plaque } \\
\text { Index }\end{array}$ & $\begin{array}{c}\text { Sites Positive } \\
\text { for Bleeding }\end{array}$ & $\begin{array}{c}\text { Sites Negative } \\
\text { for Bleeding }\end{array}$ & $\begin{array}{c}\text { GCF flow rate } \\
(\mathrm{mg} / \mathrm{min})\end{array}$ \\
\hline $\begin{array}{l}\text { Control } \\
\text { Adult Periodontitis }\end{array}$ & $1.63 \pm 0.06$ & $0.17 \pm 0.03$ & $0.18 \pm 0.03$ & $0.5 \pm 0.3$ & $27.1 \pm 0.4$ & $1.53 \pm 0.22$ \\
(AP) & $3.78 \pm 0.32$ & $2.57 \pm 0.10$ & $2.66 \pm 0.12$ & $20.2 \pm 1.91$ & $3.0 \pm 1.11$ & $2.29 \pm 0.33$ \\
Rapidly Progressive & $4.46 \pm 0.31$ & $2.85 \pm 0.07$ & $2.88 \pm 0.09$ & $23.7 \pm 1.19$ & $2.4 \pm 0.7$ & $2.93 \pm 0.24$ \\
\hline Periodontitis (RPP) & & & & & & \\
\hline
\end{tabular}

Table 2 Data related to laboratory flndings (mean \pm S. D.)

\begin{tabular}{lccc}
\hline & $\begin{array}{c}\text { Neutrophil MPO } \\
\left(\mathrm{U} / 1 \times 10^{6} / \mathrm{ml}\right)\end{array}$ & $\begin{array}{c}\text { GCF MPO } \\
(\mathrm{U} / \mathrm{mg})\end{array}$ & $\begin{array}{c}\text { Whole Saliva MPO } \\
(\mathrm{U} / \mathrm{ml})\end{array}$ \\
\hline $\begin{array}{l}\text { Control } \\
\text { Adult Periodontitis }\end{array}$ & $220.6 \pm 26.7$ & $10.61 \pm 0.69$ & $0.05 \pm 0.06$ \\
$\begin{array}{l}\text { (AP) } \\
\text { Rapidly Progressive }\end{array}$ & $583.3 \pm 88.81$ & $11.40 \pm 1.17$ & $0.11 \pm 0.02$ \\
Periodontitis (RPP) & $563.1 \pm 137.05$ & $15.13 \pm 2.34$ & $0.14 \pm 0.04$ \\
\hline
\end{tabular}

\section{Discussion}

Periodontal disease, without exception, is related to bacterial plaque, but the presence of microorganisms alone is not the only factor responsible for periodontal destruction ${ }^{[1,3,4,10]}$. Factors related to host defence are also involved in the pathogenesis of periodontal disease ${ }^{[1-3,10]}$. The killing and elimination of pathogenic bacteria is done by phagocytic cells ${ }^{[6,16,28]}$. The 
antimicrobial action of these cells can be either oxygen-dependent or independent. MPO of neutrophils is involved in their oxygen-dependent antimicrobial activity ${ }^{[20,29]}$. MPO together with $\mathrm{H}_{2} \mathrm{O}_{2}$ and halide as cofactors, constitute a microbicidal system for neutrophils and monocytes $^{[11]}$, which has been shown to be active against $E$. coli, L. acidophilus and $S$. aureus $^{[14,19]}$, as well as A. actinomycetemcomitans ${ }^{[17]}$. Previous studies have suggested that MPO activity may be involved in periodontal disease activity ${ }^{[1,21,22]}$, although the type and pattern of periodontal destruction was not identified. The present study was undertaken to determine the MPO activity in specific periodontal diseases such as RPP and AP, which present distinct clinical, microbiological and immunological features ${ }^{[30,31]}$.

All of the clinical parameters examined were found to be significantly increased in both of the patient groups when compared with the healthy subjects $(p<0.05)$. The deepest pocket depths and the highest mean scores of gingival inflammation, the highest number of sites positive for bleeding, and an elevated GCF flow rate in the RPP group $(p<0.05)$ indicated the presence of more severe periodontal breakdown. The mean MPO activity in peripheral blood neutrophils was found to be significantly increased in both of the disease groups. The difference between the RPP and AP groups was also significant $(\mathrm{p}<0.05)$. These findings are consistent with previous studies, which have suggested that MPO activity might be related to the periodontal status of patients ${ }^{[13,21,22]}$. Furthermore, the MPO of neutrophils also seemed to be related to both the severity of periodontal destruction and the type of periodontal disease, since the highest neutrophil MPO activity was detected in patients with RPP, which is known to produce rapid and severe periodontal destruction in young adults ${ }^{[30]}$.

Increased GCF MPO activity has been reported previously ${ }^{[13,21,22]}$, and similarly, in the present study, increased GCF MPO activity levels were detected in the patient groups, compared with the control group. Again, the RPP group had the highest MPO activity. This increased GCF MPO activity was attributed to the increased number of neutrophils in the periodontally diseased areas ${ }^{[13]}$. This elevation may also be related to the degranulation of neutrophils by the toxins of specific periodontopathic bacteria. Such microorganisms, for example $A$. actinomycetemcomitans, may produce cytopathic changes in the neutrophils by the release of toxins, which ultimately lead to the lysis of these cells ${ }^{[32-34]}$.

Whyte et al. ${ }^{[35]}$ have also demonstrated that in young adults with periodontal disease, peripheral blood neutrophils are present in an active state, both metabolically and functionally, when compared with the peripheral neutrophils of relatively older patients. The increased GCF and neutrophilic MPO activity detected in the present study may therfore be attributable, at least in part, to the hyperactive state of peripheral blood neutrophils following chronic antigenic stimulation.

Among the samples studied, whole saliva samples showed the lowest MPO activity, suggesting that GCF MPO is diluted during the passage of this fluid to the oral environment. Previous studies have suggested that GCF might contribute to the enzyme content of whole saliva ${ }^{[36]}$. Peripheral neutrophil suspensions had the highest MPO activity detected. MPO is found primarily in the granules of neutrophils ${ }^{[11,13,16,37]}$, and it is suggested to be an indicator of neutrophil accumulation in tissues ${ }^{[13,38]}$. Our findings also confirm that neutrophils are the major source of MPO.

The present findings, together with data from previous studies ${ }^{[13,21,22]}$ suggest a relationship between MPO and periodontal disease. Furthermore, the relatively higher neutrophil, GCF and whole saliva MPO activity detected in patients with RPP also suggests that MPO may be related to the pattern and severity of periodontal breakdown.

\section{Conclusions}

1) In the patient groups, the MPO activity in neutrophil and whole saliva samples was found to be significantly increased when compared with the control group. 
2) The highest GCF, whole saliva and neutrophil MPO activity was detected in patients with RPP.

3) Among the samples studied, neutrophils had the highest MPO activity.

4) The findings of this study, together with data from previous studies, suggest a relationship between MPO activity and periodontal disease.

\section{References}

[1] Page, R. C. and Schroeder, H. E.: Pathogenesis of inflammatory periodontal disease, Lab. Invest., 33, 235-249, 1976

[2] Page, R. C. and Schroeder, H. E.: Current status of the host response in chronic marginal periodontitis, $J$. Periodontol., 52, 477-491, 1981

[3] Genco, R. J. and Slots, J.: Host responses in periodontal diseases, J. Dent. Res., 63, 441-451, 1984

[4] Ranney, R. R.: Immunologic mechanisms of pathogenesis in periodontal diseases. An assessment, $J$. Periodont. Res., 26, 243-254, 1991

[5] Van Dyke, T. E., Horoszewitc, H. U., Cianciolai, H. J. and Genco, R. J.: Neutrophil chemotaxis dysfunction in human periodontitis, Infect. Immun., 27, 124-132, 1980

[6] Van Dyke, T. E., Levine, M. J. and Genco, R. J.: Neutrophil function and oral disease, J. Oral Pathol., 14, 95-120, 1985

[7] Murray, A. and Patters, R.: Gingival crevice neutrophil function in periodontal lesions, J. Periodont. Res., 15, $463-469,1980$

[8] Seymour, G. J., Whyte, G. J. and Powell, R. N.: Chemiluminescence in the assessment of the polymorphonuclear leukocyte function in chronic inflammatory periodontal disease, J. Oral Pathol., 15, 125-131, 1986

[9] Gilbert, A. D. and Sofaer, J. A.: Neutrophil function, genotype and periodontal bone loss in the mouse, J. Periodont. Res., 24, 412-414, 1989

[10] Seymour, G. J.: Importance of the host response in the periodontium, J. Clin. Periodontol., 18, 421-426, 1991

[11] Thomas, E. L., Grisham, M. B. and Jefferson, M. M.: Myeloperoxidase dependent effect of amines on functions of isolated neutrophils, J. Clin. Invest., 72, 441-454, 1983

[12] Weiss, S. J.: Tissue destruction by neutrophils, New Eng. J. Med., 320, 365-376, 1989

[13] CAO, C. F. and Smith, Q. T.: Crevicular fluid myeloperoxidase at healthy, gingivitis and periodontitis sites, J. Clin. Periodontol., 16, 17-20, 1989

[14] Klebanoff, S. J.: Myeloperoxidase-halide-hydrogen peroxide antibacterial system, J. Bacteriol., 95, 21312138,1968

[15] Marquez, L. A. and Dunford, B.: Reaction of compound 3 of myeloperoxidase with ascorbic acid, J. Biol. Chem., 215, 6074-6078, 1989

[16] Babior, B. M.: Oxidants from phagocytes: Agents of defence and destruction, Blood, 64, 959-966, 1984

[17] Miyasaki, T. K., Wilson, M. E. and Genco, R. J.: Killing of Actinobacillus actinomycetemcomitans by the human neutrophil myeloperoxidase-hydrogen peroxide-chloride system, Infect. Immun., 53, 161-165, 1986

[18] Stendhal, O., Coble, B. J., Dahigren, C., Hed, J. and Molin, L.: Myeloperoxidase modulates the phagocytic activity of polymorphonuclear neutrophil leukocytes. Studies with cells from myeloperoxidase-deficient patient, J. Clin. Invest., 73, 366-373, 1984

[19] Humphreys, J. M., Davies, B., Hart, A. and Edwards, S.: Role of myeloperoxidase in the killing of S. aureus by human neutrophils. Studies with the myeloperoxidase inhibitor salicylhydroxamic acid, J. Gen. Microbiol., 185, 1187-1193, 1989

[20] Kowolik, M. J. and Grant, M.: Myeloperoxidase activity in human gingival crevicular neutrophils, Arch. Oral Biol., 28, 293-295, 1983

[21] Smith, Q. T., Hinrichs, J. E. and Melynk, R. S.: Gingival crevicular fluid myeloperoxidase at periodontitis sites, J. Periodont. Res., 21, 45-55, 1986

[22] Wolff, L. F., Smith, Q. T., Synder, J. A., Bedrick, J. A., Liljemark, W. F., Aeppli, D. A. and Banat, C. L.: Relationship between lactate dehydrogenase and myeloperoxidase levels in human gingival crevicular fluid and clinical and microbial measurements, J. Clin. Periodontol., 15, 110-115, 1985

[23] LöE, H.: The Gingival index, the plaque index and the retention index systems, J. Periodontol., 38, 610-616, 1967

[24] Rudin, H. J., Overdiek, H. F. and Rateitschak, K. H.: Correlation between sulcus fluid rate and clinical and histological inflammation of the marginal gingiva, Helv. Odont. Acta, 14, 21-26, 1970

[25] Bоyum, B.: Separation of leukocytes from blood and bone marrow, Scand. J. Clin. Lab. Invest., 21 Suppl., 97, 1968

[26] Hanker, J. S., Laszlo, J. and Moore, J. O.: The Light microscopic demonstration of hydroperoxidasepositive phi bodies and rods in leukocytes in acute myeloid leukemia, Histochemistry, 58, 241-244, 1978 
[27] Cohen, L. and Holliday, M.: Statistics for Social Scientists, London, Harper and Row, 1983

[28] Rakita, R., Michel, B. R. and Rosen, H.: Differential inactivation of $E$. coli membrane dehydrogenases by myeloperoxidase - Mediated antimicrobial system, Biochemistry, 29, 1075-1080, 1990

[29] Fenna, R. E.: Crystallization and subunit structure of canine myeloperoxidase, J. Mol. Biol., 196, 919-925, 1987

[30] Page, R. C., Altman, L. C., Ebersole, J. L., Vandesteen, G. E., Dahlberg, W. H., Willmans, B. L. and Osterberg, S. K.: Rapidly Progressive Periodontitis: A distinct clinical condition, Periodontol., 54, 197-209, 1983

[31] Schluger, S., Yuodelis, R., Page, R. C. and Jonhson, R.: Periodontal Diseases: Basic Phenomena, Clinical Management and Occlusal and Restorative Interrelationships, 67-68, 228, Lea and Febiger, Philadelphia, London, 1990

[32] Tsai, C. C., McArthur, W. P. and Baehni, P. C.: Extraction and partial characterization of a leukotoxin from a plaque-derived gram-negative microorganism, Infect. Immun., 25, 427-439, 1979

[33] Taichman, N. S., Shenker, B. J., Tsai, C. C., Glickman. L. T., Baehni, P. C., Stevens, R. and Hammont, B. F.: Cytopathic effect of Actinobacillus actinomycetemcomitans on monkey blood leukocytes, J. Periodont. Res., 19, 133-145, 1984

[34] Sandholm, L. K. and SAxEN, L.: Ultrastructure of freeze-fractured neutrophil leukocyte membranes in juvenile periodontitis, J. Periodont. Res., 19, 269-278, 1989

[35] Whyte, G. J., Seymour, G. J., Cheung, K. and Robinson, M. F.: Chemiluminescence of peripheral polymorphonuclear leukocytes from adult periodontitis patients, J. Clin. Periodontol., 16, 69-74, 1989

[36] Nakamura, M. and Slots, J.: Salivary enzymes: Origin and relationship to periodontal disease, J. Periodont. Res., 18, 559-569, 1983

[37] Zuurbier, K. W. M., Bakkanist, A. R. J., Wever, R. and Muissers, A. D.: The chlorinating activity of human myeloperoxidase: High initial activity at neutral $\mathrm{pH}$ value and activation by electron donors, Biochim. Biophys. Acta, 1037, 140-146, 1990

[38] Schierwagen, C., Bylund-fellenius, A. C. and Lundberg, C.: Improved method for quantification of tissue PMN accumulation measured by myeloperoxidase activity, J. Pharm. Met., 23, 166-179, 1990 